This item was submitted to Loughborough's Research Repository by the author.

Items in Figshare are protected by copyright, with all rights reserved, unless otherwise indicated.

\title{
Influence of microstructure on cavitation in the heat affected zone of a Grade 92 steel weld during long-term high temperature creep
}

\section{PLEASE CITE THE PUBLISHED VERSION}

https://doi.org/10.1016/j.matchar.2020.110663

\section{PUBLISHER}

Elsevier BV

VERSION

AM (Accepted Manuscript)

\section{PUBLISHER STATEMENT}

This paper was accepted for publication in the journal Materials Characterization and the definitive published version is available at https://doi.org/10.1016/j.matchar.2020.110663.

\section{LICENCE}

CC BY-NC-ND 4.0

\section{REPOSITORY RECORD}

Xu, X, JA Siefert, JD Parker, and Rachel Thomson. 2020. "Influence of Microstructure on Cavitation in the Heat Affected Zone of a Grade 92 Steel Weld During Long-term High Temperature Creep". Loughborough University. https://hdl.handle.net/2134/13101809.v1. 


\section{Influence of microstructure on cavitation in the heat affected zone of \\ 2 a Grade 92 steel weld during long-term high temperature creep}

3 X. Xu ${ }^{1 *}$, J.A. Siefert ${ }^{2}$, J.D. Parker ${ }^{2}$ and R.C. Thomson ${ }^{\text {*** }}$

$4 \quad{ }^{1}$ Department of Materials, Loughborough University, Loughborough, LE11 3TU, UK

$5 \quad$ 2EPRI, 1300 Harris Boulevard, Charlotte, North Carolina, 28262, USA

$6 \quad *$ Corresponding author: xu.xu@manchester.ac.uk

$7 \quad * *$ Corresponding author: r.c.thomson@lboro.ac.uk

8 Keywords

$99 \%$ Cr tempered martensitic steel, heat affected zone, high temperature creep, creep

10 cavitation, welding

\section{Highlights:}

- Creep damage in the heat affected zone of a multi-pass Grade 92 steel weld was evaluated after long-term creep exposure.

- Creep damage was compared with the variation of microstructure in the heat

$$
\text { affected zone. }
$$

- Cavitation preferentially occurs in the regions showing a refined microstructure with an inhomogeneous distribution of the $\mathrm{M}_{23} \mathrm{C}_{6}$ carbides.

- Creep cavities are preferentially formed on the $\mathrm{Al}_{2} \mathrm{O}_{3}, \mathrm{MnS}$ and $\mathrm{BN}$ particles.

- The partially transformed zones are the most susceptible to creep cavitation.

\section{Abstract}

21 The microstructure in the heat affected zone of the multi-pass welds constructed by using the

$229 \% \mathrm{Cr}$ tempered martensitic steels is complex and susceptible to premature creep failure. In

23 the present research, a systematic investigation has been conducted after long-term creep 
24 exposure in the heat affected zone of a multi-pass weld on the $9 \% \mathrm{Cr}$ Grade 92 steel to 25 identify the sub-optimal microstructures with a high susceptibility to creep cavitation. The 26 characterisation techniques employed include hardness mapping and a range of electron27 based microscopy techniques to provide quantitative data of microstructure and creep cavity. 28 In this case, preferential creep cavitation has been confirmed in the regions within the heat 29 affected zone that possess a microstructure with an inhomogeneous distribution of the $\mathrm{M}_{23} \mathrm{C}_{6}$ 30 carbides and a refined martensitic grain structure. Creep cavities have been observed on the 31 secondary phase particles including the $\mathrm{Al}_{2} \mathrm{O}_{3}$, the $\mathrm{MnS}$ and the $\mathrm{BN}$ phases. In addition, no 32 clear trends have been observed between creep cavity and the variation of hardness or the

33 Laves phase particles in the heat affected zone. The observations from the current research 34 confirm that creep cavitation preferentially occurs in the partially-transformed zones that were subjected to thermal cycles associated with peak temperatures between the $\mathrm{Ac}_{1}$ and the

$36 \mathrm{Ac}_{3}$ transus temperatures during weld fabrication.

\section{1. Introduction}

38 The 9\% Cr tempered martensitic steels have been used in a range of applications in the 39 power generation industry because of their excellent creep strength and good corrosion

40 resistance. These materials are usually used to construct the components in the steam

41 pipeline system such as pipes, tubes and headers [1]. The thermo-mechanical processing 42 utilised for the fabrication of the industrial components normally involves forging, 43 normalisation and tempering. In addition, sophisticated multi-pass welding technique is 44 commonly used for thick-section applications to produce complicated welds with 45 satisfactory mechanical properties for long-term applications at elevated temperatures > $46550{ }^{\circ} \mathrm{C}[2,3]$. The $9 \% \mathrm{Cr}$ steels are compatible with a range of welding processes available 47 for industrial applications including Sub-merged Arc Weld (SAW), Gas Tungsten Arc 48 Welding (GTAW) and Shielded Metal Arc Welding (SMAW) [2].

49 The microstructure of the $9 \%$ Cr steels is typically composed of a tempered martensitic 50 matrix in combination with the strengthening precipitate particles that are evenly 51 distributed on grain boundaries and within the grain interiors [1]. However, the 
52 microstructure within the Heat Affected Zone (HAZ) of weldments is extremely complex

53 due to the complicated thermal and stress experiences for the local materials during

54 welding. The microstructural regions that arise in the HAZ are commonly categorised

55 based on the variation of grain size into the Coarse Grain (CG), Fine Grain (FG), Inter-

56 Critical (IC) and Sub-Critical (SC) regions [4,5]. This description of the HAZ provides a

57 generalised classification of microstructure in the weldments made from low alloy ferritic

58 and bainitic steels, and have continued to be adopted in the studies on the family of 9-12

59 wt. \% Cr steel weldments [5-7].

60 The premature creep failure occurred in the HAZ is a known problem to $9 \% \mathrm{Cr}$ steel welds,

61 in which creep cavitation preferentially takes place in the HAZ regions that are close to the

62 boundary with the parent metal $[4,5,8,9]$. The effect of microstructure on creep cavitation

63 has been extensively investigated to understand the factors contributing to the formation of

64 cavities in the HAZ. For instance, it is revealed that cavitation is promoted in the regions

65 showing low hardness and a refined grain structure [10-12]. Creep cavitation is also

66 promoted in the regions showing an inhomogeneous distribution of strengthening

67 precipitate particles on lath and grain boundaries [13-17]. In addition, the secondary phase

68 particles above a critical size are also related to creep cavitation as they act as the preferred

69 sites for cavity nucleation [16-22]. These detrimental phases include the $\mathrm{Al}_{2} \mathrm{O}_{3} / \mathrm{MnS}$

70 inclusions, the $\mathrm{BN}$ phases and the $\mathrm{M}_{23} \mathrm{C}_{6}$ carbides or the Laves phases that are coarsened

71 during creep [17,18,21]. In particular, cavities are preferentially developed on the BN

72 particles in the HAZ of Grade 92 steel welds [22]. These cavities formed in the early stage

73 of creep significantly deteriorate creep ductility and are coalesced to form macro-cracks at

74 the end of creep life [22].

75 Detailed metallographic observations in the existing studies on $9 \% \mathrm{Cr}$ steel welds have

76 provided the basis for understanding premature creep failure in the HAZ, while the key

77 factors contributing to cavitation are still under debate and not completely understood. For

78 instance, creep tests conducted at different temperature and stress conditions indicate that

79 creep failure is not always occurred in the HAZ regions showing the lowest hardness

$80[5,23,24]$. Other studies also demonstrate the cases of weldments not ruptured in the regions 
81 possessing the most refined grain structure $[25,26]$. In addition, there is a lack of a systematic study to identify typical characteristics of sub-optimal microstructures being

83 susceptible to cavitation with a clear link to the thermal experiences during welding.

84 To understand the critical link with the history of thermal experiences, the microstructure in 85 the HAZs of Grade 92 steel welds has been systematically investigated to correlate with 86 bulk materials after the thermal experiences that simulate typical thermal cycles during 87 welding [15,27]. These systematic observations have led to a detailed description for the 88 microstructure in the HAZ that is divided into three distinct regions: the Completely 89 Transformed Zone (CTZ), the Partially Transformed Zone (PTZ) and the Over-Tempered 90 Zone (OTZ) [15]. The microstructure of the CTZ is produced upon a weld thermal cycle 91 associated with a peak temperature above the $\mathrm{Ac}_{3}$ transus temperature, giving rise to a fully 92 re-austenitised martensitic matrix and a complete dissolution of the pre-existing precipitate 93 particles. The PTZ experiences a thermal cycle associated with an inter-critical peak 94 temperature between the $\mathrm{Ac}_{1}$ and the $\mathrm{Ac}_{3}$ temperatures, which leads to a partially re95 austenitised martensitic matrix together with partial dissolution of the pre-existing 96 precipitates. The OTZ has a grain structure that is similar to the original matrix in the 97 parent metal, whilst the pre-existing precipitate particles are slightly coarsened after 98 experiencing thermal cycles with a peak temperature below the $\mathrm{Ac}_{1}$ temperature [15]. As 99 such, an accurate description of the HAZ microstructure in Grade 92 steel welds has been 100 established by classifying the HAZ into three regions that are related to where the peak 101 temperature of weld thermal cycles in relation to the $\mathrm{Ac}_{1}$ and the $\mathrm{Ac}_{3}$ temperatures.

102 Following the previous studies detailing the initial microstructure in the as-fabricated 103 condition, the present research systematically investigates the microstructure in the HAZ of 104 Grade 92 steel welds after long-term creep exposure. This, in turn, establishes the critical 105 link between the initial and ex-service microstructures and facilitates a clear definition for 106 the regions being the most susceptible to cavitation in the HAZ of multi-pass Grade 92 steel 107 welds. The characterisation techniques employed include hardness mapping and a range of 108 electron-based microscopy techniques to provide quantitative data of microstructure and 
109 creep damage. The correlation between creep damage and microstructure leads to a clear

110 identification of the critical metallurgical factors related with the formation of cavities.

\section{2. Materials and experimental procedure}

\section{2.1. Materials}

113 A circumferential multi-pass weld joint was fabricated in the Grade 92 steam pipe using the 114 typical procedures utilised for industrial applications. The heat treatment of the pipe 115 material involves a normalisation process at $1065{ }^{\circ} \mathrm{C}$ and a tempering process at $777^{\circ} \mathrm{C}$.

116 The chemical composition of the material was examined by using the Inductively Coupled 117 Plasma (ICP) analysis with the results detailed in Table 1.

118 Table 1. Experimentally measured chemical composition (wt. \%) of the bulk material in a thick-section 119 Grade 92 steam pipe using ICP-OE and ICP-MS, the balance is Fe.

\begin{tabular}{ccccc}
\hline $\mathrm{Cr}$ & $\mathrm{Mn}$ & $\mathrm{Mo}$ & $\mathrm{Nb}$ & $\mathrm{Ni}$ \\
8.860 & 0.490 & 0.420 & 0.074 & 0.400 \\
\hline $\mathrm{N}$ & $\mathrm{Al}$ & $\mathrm{Cu}$ & $\mathrm{P}$ & $\mathrm{S}$ \\
0.047 & 0.006 & 0.160 & 0.015 & 0.003 \\
\hline $\mathrm{Si}$ & $\mathrm{V}$ & $\mathrm{W}$ & $\mathrm{C}$ & $\mathrm{B}$ \\
0.270 & 0.228 & 1.760 & 0.110 & 0.004 \\
\hline $\mathrm{Ca}$ & $\mathrm{Co}$ & $\mathrm{Ti}$ & $\mathrm{Zr}$ & $\mathrm{Sn}$ \\
0.001 & 0.025 & 0.004 & 0.004 & 0.009 \\
\hline
\end{tabular}

121 The fabrication of the weld joint involves the initial root passes conducted by using SMAW 122 and an automated multi-pass SAW process for the subsequent fill passes. The filler 123 materials utilised were an E9015-B9 and an ER90S-B9 filler for the SMAW and the SAW 124 processes, respectively. The fill passes were performed at a voltage of $30 \mathrm{~V}$ and an 125 amperage of 400 A. Seventy-two weld beads were deposited as the electrode travelling at a 126 speed of $381 \mathrm{~mm} / \mathrm{min}$. The Post Weld Heat Treatment (PWHT) was conducted at $732{ }^{\circ} \mathrm{C}$ 127 for 2 hours. 
128 Flat specimens were machined from the weld joint with a gauge length of $100 \mathrm{~mm}$, a width

129 of $60 \mathrm{~mm}$, and a gauge thickness of $9 \mathrm{~mm}$, Figure 1a. The gauge included the entire weld

130 deposit with the fusion boundary at $\sim 90^{\circ}$ to the stress loading direction. The high-

131 temperature creep exposure of cross-weld specimens was carried out at $625{ }^{\circ} \mathrm{C}$ at a loading

132 of uniaxial tension of $80 \mathrm{MPa}$. (EPRI: please add the details to indicate the locations used

133 for the measurement of strain and strain rate) The creep testing was stopped at $\sim 5,000, \sim$

1348,000 and $\sim 11,000$ hours for detailed examinations of microstructure and creep damage.

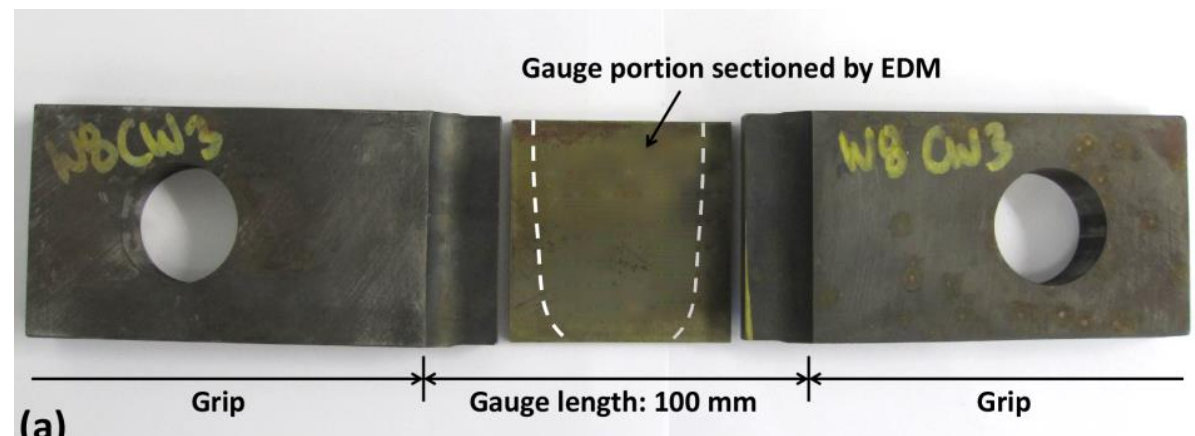

(a)

1: sectioning of gauge portion

2: bisected in the mid-thickness plane

(b)
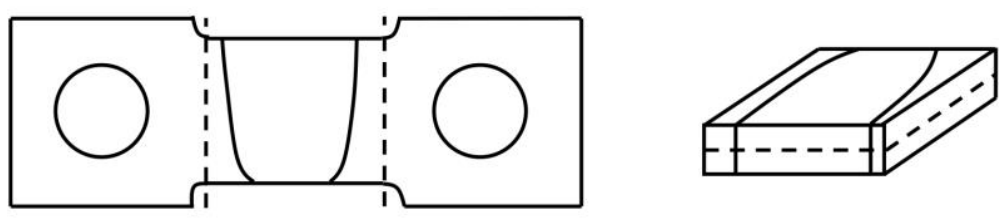

136 Figure 1. (a) A picture showing a flat specimen containing the weld and the HAZ in the centre of gauge

137 portion. The white dash lines indicate the location of fusion boundaries. (b) Schematic diagrams

138 illustrating the sectioning of gauge position for detailed metallographic observations.

\subsection{Microstructural characterisation}

140 The gauge portions were extracted from the cross-weld specimens and further bisected in

141 the mid-thickness plane for microstructural examination after creep exposure, Figure $1 \mathrm{~b}$.

142 The surfaces of gauge portions were prepared by using the standard metallographic

143 preparation methods involved with grinding on $\mathrm{SiC}$ with water used as lubricant and

144 polishing in the $3 \mu \mathrm{m}$ and $1 \mu \mathrm{m}$ diamond suspensions. A chemo-mechanical polishing 
145 process was subsequently performed by using the $0.06 \mu \mathrm{m}$ colloidal silica suspension to 146 achieve a surface finish suitable for EBSD analysis.

147 Hardness mapping was conducted by using a Struers Durascan 70 hardness testing system 148 to identify the microstructural variation in the weld. The testing was carried out with a 149 Vickers indenter operated at a test load of $0.2 \mathrm{~kg}$ with a uniform spacing of $0.1 \mathrm{~mm}$. The 150 testing condition used in the present research is consistent with the previous tests on the 151 identical materials as detailed in [28]. Hardness mapping was carried out over an area of $15210 \times 5 \mathrm{~mm}$ to ensure an accurate representation of the hardness in the weld metal, the HAZ 153 regions, and the parent metal. The post analysis of the hardness data was performed by 154 using the Origin software version $2020 \mathrm{~b}$.

155 A FEI Nova 600 Nanolab dual beam Focused Ion Beam (FIB)/Field Emission Gun (FEG)156 SEM was used to characterise creep cavity, grain structure and secondary phase particles. 157 An overview of the gauge portion was firstly achieved by using Backscattered Electron 158 (BSE) imaging at an accelerating voltage of $10 \mathrm{kV}$. The BSE micrographs were collected 159 sequentially over an area of $\sim 60 \times 60 \mathrm{~mm}$ at a pixel resolution of $\sim 2 \mu \mathrm{m}$ through the 160 automated image acquisition capability of the FIB/FEG-SEM instrument. The BSE 161 micrographs were then stitched to generate a large-scale montage by using the ImageJ 162 software version $1.47 \mathrm{t}$, providing an overview of the entire gauge portion. The quantitative 163 analysis of creep cavity was carried out by using BSE imaging at a pixel resolution of $\sim 0.2$ $164 \mu \mathrm{m}$. BSE micrographs were collected sequentially against the fusion boundary with a 165 spacing of $0.25 \mathrm{~mm}$ with each covering an area of $\sim 250 \times 200 \mu \mathrm{m}$. The number density 166 and average size of the cavities were characterised by using a grey scale segmentation 167 method utilising the ImageJ software. The minimum size of the cavities included for the 168 analysis is $\sim 0.5 \mu \mathrm{m}$. In addition, the distribution characteristics of the $\mathrm{Fe}_{2}(\mathrm{~W}, \mathrm{Mo})$ Laves 169 phases were investigated by using BSE imaging at the identical conditions utilised for 170 cavity analysis. The quantitative analysis of Laves phases was carried out a grey scale 171 segmentation method utilising the ImageJ software, with the minimum size (i.e. Feret's 172 diameter) of the particles included for the analysis at $\sim 0.5 \mu \mathrm{m}$. The secondary phase 173 particles within creep cavities were investigated by using BSE imaging at an accelerating 
174 voltage of $5 \mathrm{kV}$, with the quantitative analysis of these particles carried by using the ImageJ

175 software. The chemical analysis of these particles was further performed by using Energy

176 Dispersive X-ray (EDX) spectroscopy. This was conducted by using an Oxford

177 Instruments ${ }^{\circledR}$ Xmats 80 SDD EDX system operated at an accelerating voltage of $10 \mathrm{kV}$ to

178 minimise the inferences from the surrounding matrix.

179 The quantitative analysis of grain structure was performed by using Electron Backscatter

180 Diffraction (EBSD) with an EDAX Hikari XP camera at an accelerating voltage of $20 \mathrm{kV}$.

181 Large-scale mapping of the matrix was carried out over an area of $\sim 4 \times 1 \mathrm{~mm}$ with a step

182 size of $2 \mu \mathrm{m}$ to achieve an overview of the HAZ microstructure. The grain structure was

183 further characterised in detail by using EBSD mapping at a step size of $0.1 \mu \mathrm{m}$ over an area

184 of $100 \times 50 \mu \mathrm{m}$. The post analysis of the EBSD data was conducted by using the TSL OIM

185 analysis software version 7.2.1. The correlative analysis of the $\mathrm{M}_{23} \mathrm{C}_{6}$ carbides particles was

186 performed by using ion induced Secondary Electron (SE) imaging in the regions where the

187 EBSD analyses were performed. The ion beam was operated at an accelerating voltage of

$18830 \mathrm{kV}$ with a nominal beam current of $50 \mathrm{pA} . \mathrm{A} \mathrm{XeF}_{2}$ gas flow was used to enhance the

189 contrast differential between the $\mathrm{M}_{23} \mathrm{C}_{6}$ carbides and the surrounding matrix [15,29]. The

190 quantitative analysis of the $\mathrm{M}_{23} \mathrm{C}_{6}$ carbides was then carried out by using a grey scale

191 segmentation method to obtain their number density and average size (i.e. Feret's diameter)

192 utilising the ImageJ software version 1.47t. The minimum size of the particles included for 193 the analysis is $\sim 50 \mathrm{~nm}$.

\section{3. Results}

195 3.1. Creep exposure

196 The cross-weld specimens were exposed to high-temperature creep with a loading of

197 uniaxial tension at $625^{\circ} \mathrm{C}$ and $80 \mathrm{MPa}$. Figure 2 shows the creep strain and instantaneous

198 creep rate versus time curves for the cross-weld specimens being tested up to $~ 11,000$

199 hours. 

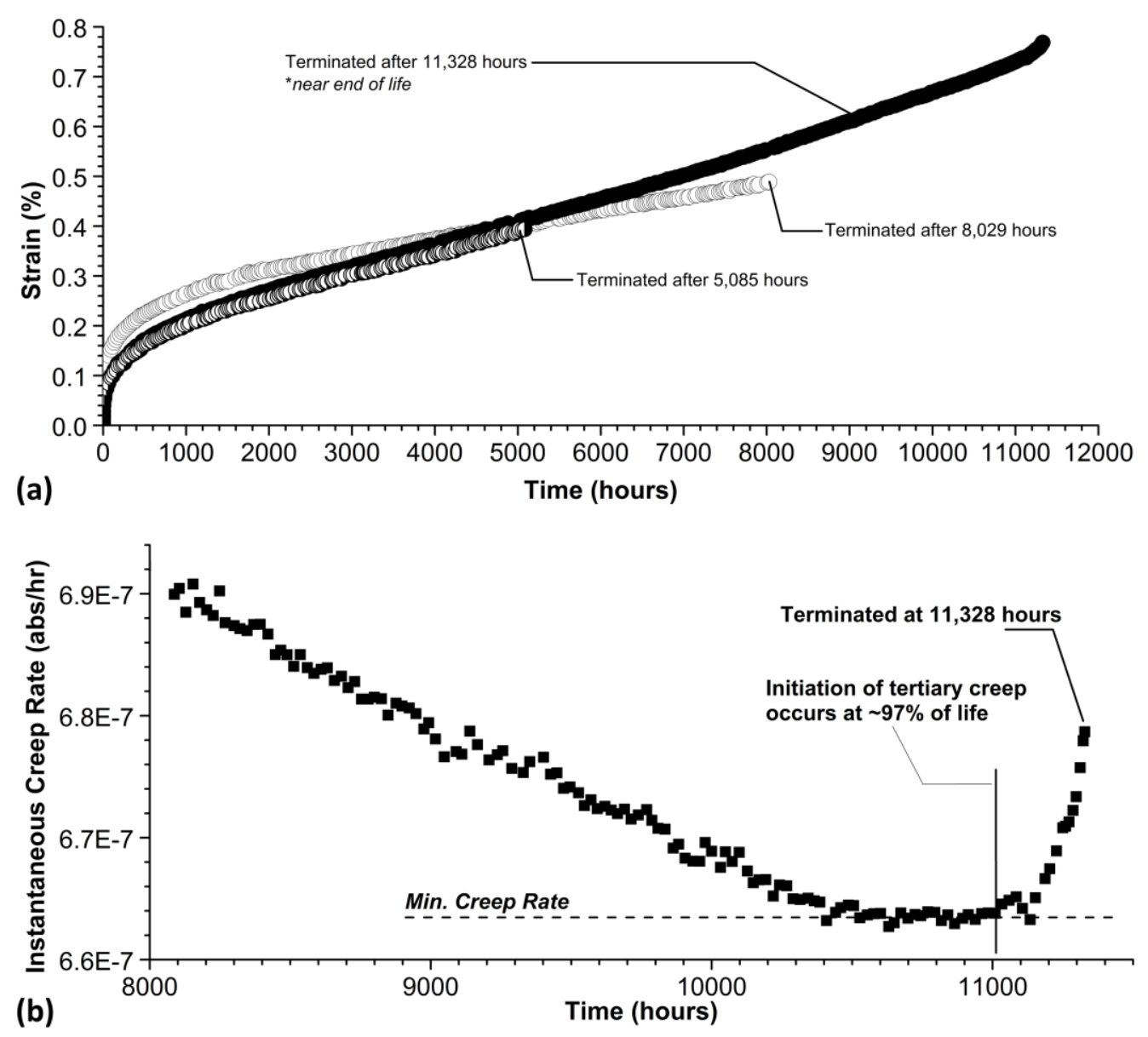

Figure 2. Graphs showing the time dependent curves of (a) creep strain and (b) instantaneous creep

202 rate for the cross-weld specimens tested up to $\sim 5,000, \sim 8,000$ and $\sim 11,000$ hours. Note: the reported

203 strain values are averaged over an effective gauge length of $80 \mathrm{~mm}$ that includes the weld, both HAZs,

204 and a portion of the base material on either side of the weld.

205 Figure 2a shows that the longest test was stopped when the rupture of specimen was

206 deemed imminent, whilst the tests terminated at $\sim 5,000$ and 8,000 hours are within the

207 stage of steady state creep. These tests were terminated at an estimated life fraction of

$20850 \%$ (5,085 hours), 80\% (8,029 hours) and > 97\% (11,328 hours) based on the experience

209 with previous cross-weld testing on the 9\% Cr tempered martensitic steels [30]. The

210 minimum creep strain rate was reached at $\sim 10,600$ hours close to the onset of the tertiary

211 creep stage, Figure 2b. 
213 Overview of microstructure and creep damage distribution in cross-weld specimens was

214 obtained by using BSE imaging. Figure 3 shows a large-scale montage of the BSE

215 micrographs showing the entire gauge portion after $\sim 11,000$ hours of creep exposure

216 together with the graphs presenting the number density and size of creep cavities across the

217 HAZs after 5,000, 8,000 and 11,000 hours of creep exposure.
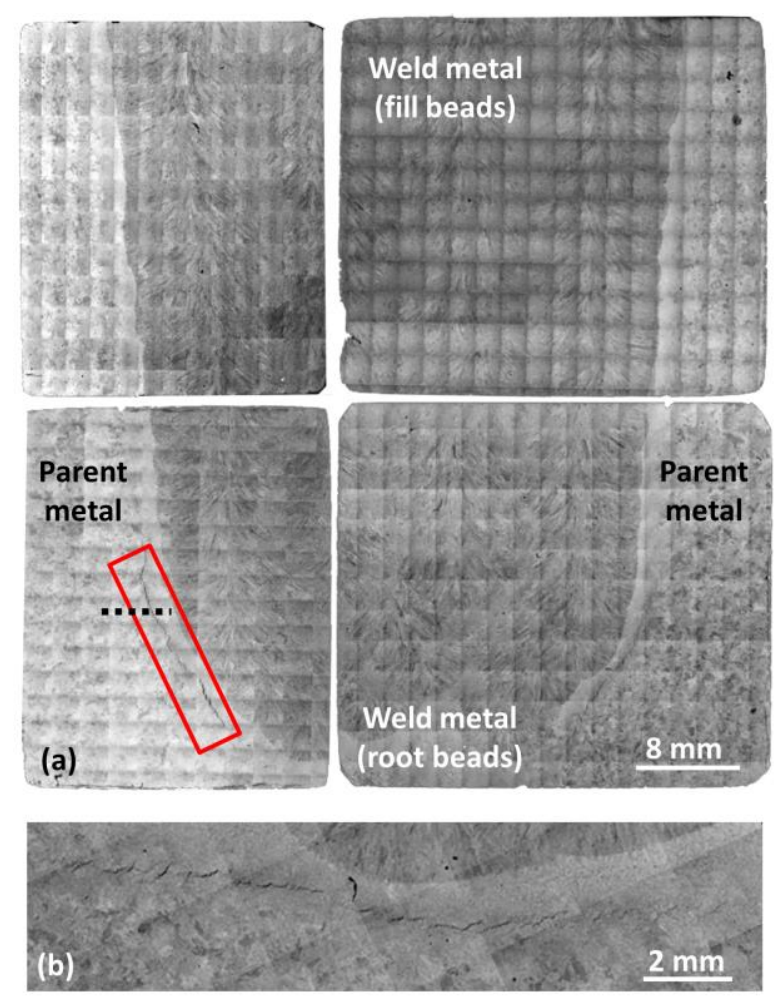
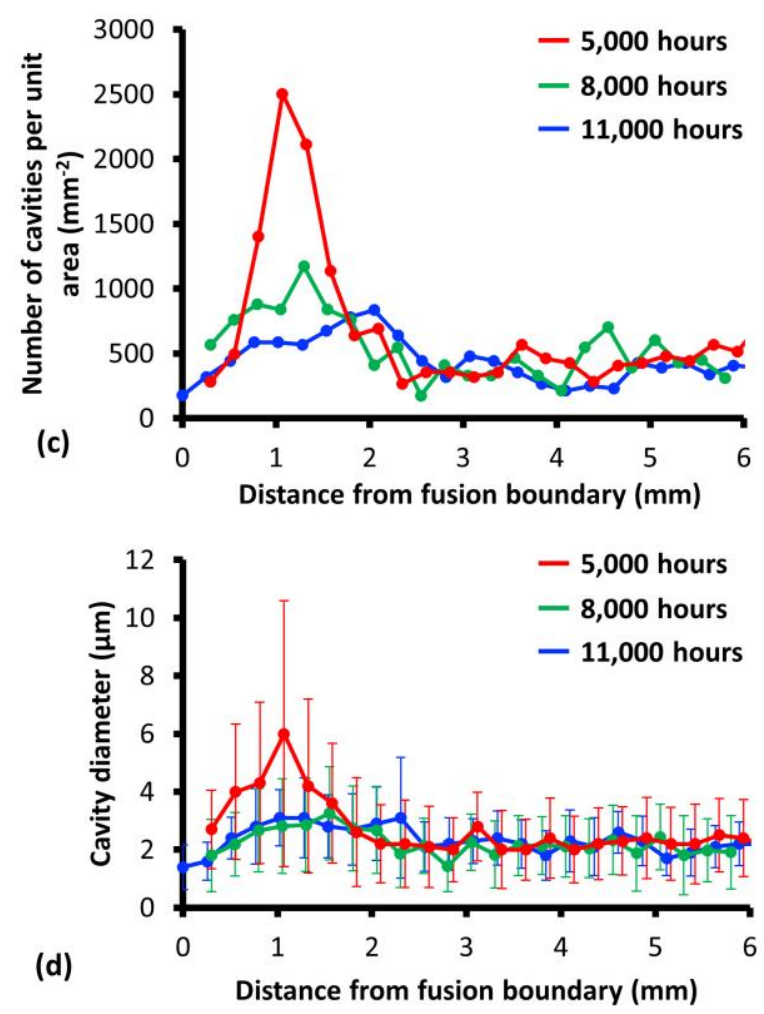

219 Figure 3. (a) A large-scale montage of BSE micrographs showing the entire gauge portion after $\sim 11,000$

220 hours of creep exposure. The primary creep crack as indicated by the red box is detailed in (b). The

221 graphs showing (c) the number per unit area and (d) the size of creep cavities after $\sim 5,000, \sim 8,000$ and

$222 \sim 11,000$ hours of creep exposure are included to demonstrate the variation of creep cavities in the

223 region as indicated by the dash line in (a). The lengths of error bars in (d) indicate the values of

224 standard deviation.

225 Figure 3a shows the primary creep damage present near the bottom of weld after $\sim 11,000$

226 hours of creep exposure. The crack is located at a distance of $1-2 \mathrm{~mm}$ away from the

227 fusion boundary, Figure 3b. The number density and size of creep cavities are similar 
228 between the specimens experiencing 5,000 and 8,000 hours of creep exposure, both

229 showing slightly higher number density and larger size for the cavities $1-2 \mathrm{~mm}$ from the

230 fusion boundary, Figures 3c and 3d. A higher level of creep damage in the HAZ suggests

231 that cavities are preferentially formed from the early stage of creep before a life fraction of

$232 \sim 50 \%$ was reached. The similarity between the specimens with $\sim 5,000$ and $\sim 8,000$ hours

233 of creep exposure further suggests that the number density of cavities has reached a

234 saturated level and remains stable during the steady state regime. In the late stage of creep

235 that are close to life end (i.e. > 95\%), a higher number density and a larger size of defect-

236 like features were observed in the local regions at $1-2 \mathrm{~mm}$ from the fusion boundary. This

237 is due to the formation of plasticity induced micro-voids and the micro/macro-cracks that

238 are formed via the link-up of cavities [12,31,32]. While the micro-voids and cracks are not

239 the direct cause of creep rupture as they were formed in the very late stage of creep, the

240 cavities that were formed in the early stage are expected to play an important role on creep

241 failure.

242 3.3. Comparison between hardness and creep cavity

243 The variation of hardness in the HAZ has been correlated with creep cavity. Figure 4

244 presents the hardness maps together with the graphs showing the trends of hardness and the

245 variations in number density and size for the creep cavity within the HAZ. 
(a)

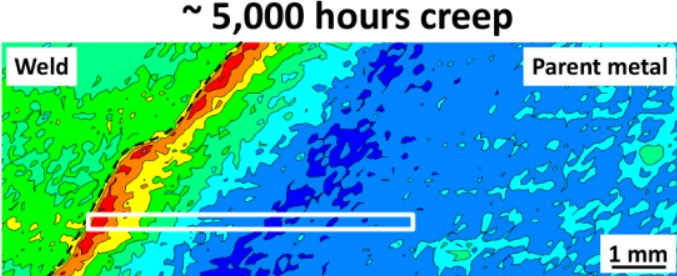

$\mathrm{HV}_{0.2}$

190205220235250265280295310

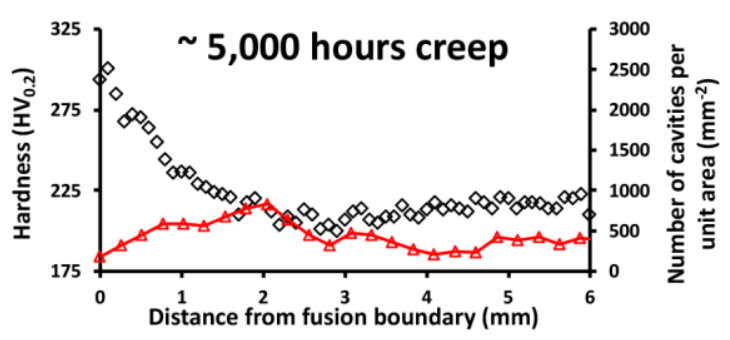

(c)

$\diamond$ Hardness $\triangle$ Number of cavities per unit area

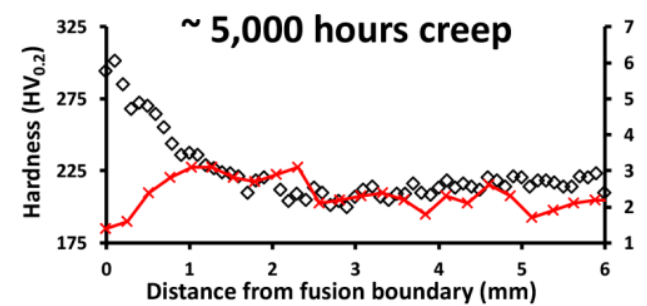

(e) (b)

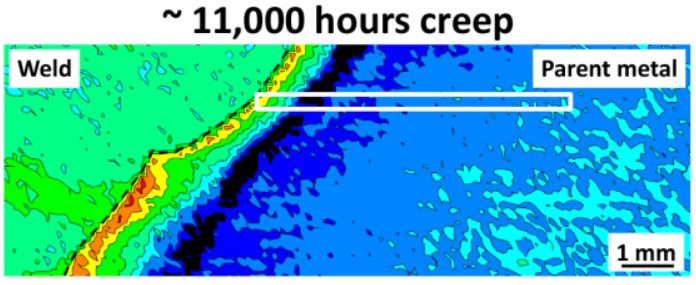

\begin{tabular}{l|lllllll}
$\mathrm{HV}_{0.2}$ & $\mathrm{I}$ & $\mathrm{I}$ & $\mathrm{I}$ & $\mathrm{I}$ & $\mathrm{I}$ & $\mathrm{1}$ & $\mathbf{1}$
\end{tabular}

190205220235250265280295310

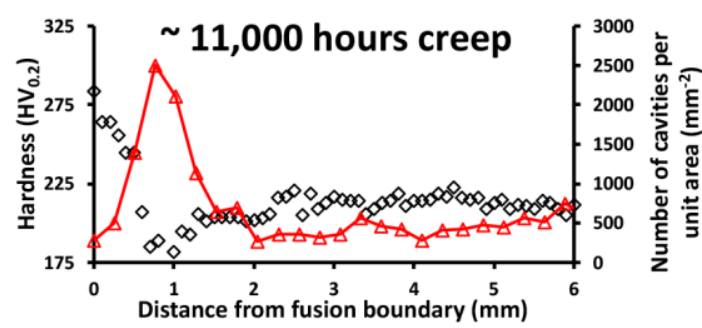

(d)

(f)

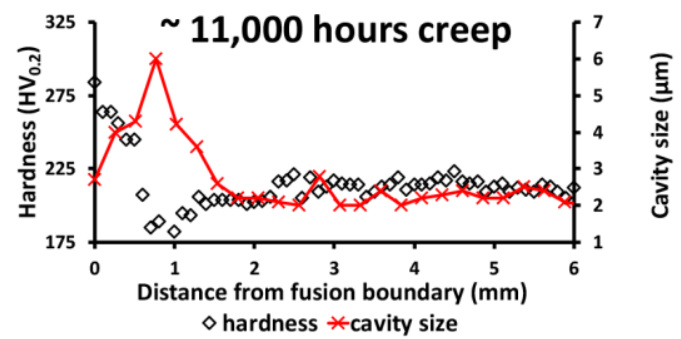

247 Figure 4. Hardness maps showing the variation of hardness after (a) 5,000 hours and (b) $\sim 11,000$

248 hours of creep exposure. The trends of hardness in the regions as indicated by white boxes are further

249 compared with the variations of (c and d) number per unit area and (e and f) size of cavities.

250 Figures $4 \mathrm{a}$ and $4 \mathrm{~b}$ show that the hardness within the HAZ is in the range of $190-319 \mathrm{HV}_{0.2}$

251 and $176-282 \mathrm{HV}_{0.2}$ after $\sim 5,000$ hours and $\sim$ 11,000 hours of creep exposure, respectively.

252 The regions showing a higher level of creep damage are not correlated with the softest

253 region and possess a hardness of $220-235 \mathrm{HV}_{0.2}$ in the specimen experiencing $\sim 5,000$

254 hours of creep exposure, Figures $4 \mathrm{c}$ and $4 \mathrm{e}$. The location of peak damage is correlated with

255 the regions showing the lowest hardness in the specimen with $\sim 11,000$ hours of creep

256 exposure, Figures 4d and 4f. 
258 The grain structure in the HAZ was analysed by using EBSD after 11,000 hours of creep 259 exposure. Figure 5 shows an EBSD overview of grain structure in the HAZ together with 260 the maps detailing the characteristics of grain structure.

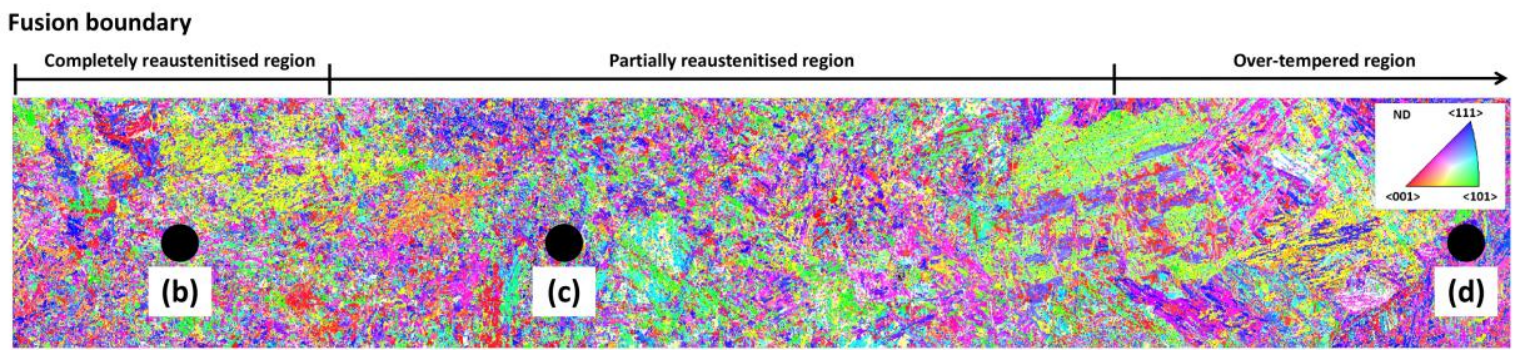

(a)

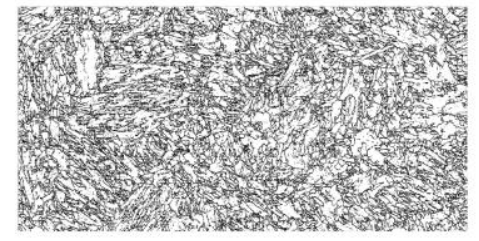

(b)

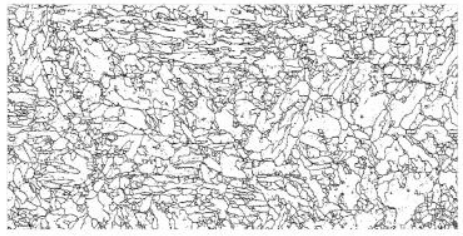

(c)

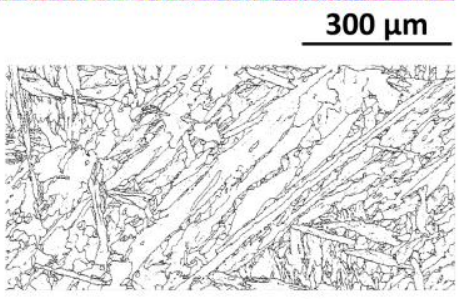

(d)

$50 \mu \mathrm{m}$

Figure 5. (a) An EBSD orientation map showing the overall gradient of grain structure in the HAZ. EBSD grain boundary maps were also obtained from the regions as labelled in (a) to provide details of grain boundary $\left(>2^{\circ}\right)$ at (b) $0.3 \mathrm{~mm}(\mathrm{CTZ}),(\mathrm{c}) 1.0 \mathrm{~mm}(\mathrm{PTZ}),(\mathrm{d}) 3.0 \mathrm{~mm}(\mathrm{OTZ})$ from the fusion boundary.

266 Figure 5a shows that the HAZ is within a distance of $3 \mathrm{~mm}$ from the fusion boundary. The grain structure within the HAZ is more refined as compared to the parent metal, which is consistent with the previous observations in the HAZ of Grade 92 steel welds prior to creep

$269[15,27]$. Figure 5b shows a refined grain structure composed of the grains $<10 \mu \mathrm{m}$ in

270 length in the region $\sim 0.3 \mathrm{~mm}$ from the fusion boundary, whilst a duplex grain structure

271 composed of the coarser lath-like grains $10-15 \mu \mathrm{m}$ in length and the smaller grains $<3 \mu \mathrm{m}$ 272 in diameter was observed in the region $\sim 1.0 \mathrm{~mm}$ from the fusion boundary, Figure $5 \mathrm{c}$. The 273 martensitic matrix in the region at $\sim 3 \mathrm{~mm}$ from the fusion boundary is considerably coarser 274 and predominantly composed of the lath-like grains $>15 \mu \mathrm{m}$ in length and $>2 \mu \mathrm{m}$ in width,

275 Figure 5d. Based on the general trend of microstructure as detailed in Figure 5a, it is 276 proposed that the HAZ is classified based on the observation from the initial weld HAZ as 
277 detailed in the previous studies $[15,27]$. The grain structure in the regions $<0.5 \mathrm{~mm}$ from

278 the fusion boundary is similar to the microstructure as produced after thermal cycles with a

279 peak temperature above the $\mathrm{Ac}_{3}$ temperature. In addition, the duplex microstructure in the

280 regions at $0.5-2.5 \mathrm{~mm}$ from the fusion boundary evidences the partial re-austenitisation

281 arising from the experience to thermal cycles with a peak temperature between the $\mathrm{Ac}_{1}$ and

282 the $\mathrm{Ac}_{3}$ temperatures during welding. The microstructure at $>2.5 \mathrm{~mm}$ from the fusion

283 boundary is not significantly varied from the original microstructure of the parent metal

284 upon the experience to thermal cycles with peak temperatures below the $\mathrm{Ac}_{1}$ temperature.

285 Creep cavities are further compared with the characteristics of grain boundary in the HAZ.

286 Figure 6 presents the graphs showing the variation of creep cavity and the length density of

287 grain boundary against the distance from fusion boundary. The length density of grain

288 boundary is decreased in the HAZ against the distance from fusion boundary after 5,000

289 and $\sim 11,000$ hours of creep exposure. It is clear that the regions with the most significant

290 creep damage are not correlated with the peak of grain boundary density in the CTZ

291 regions. 


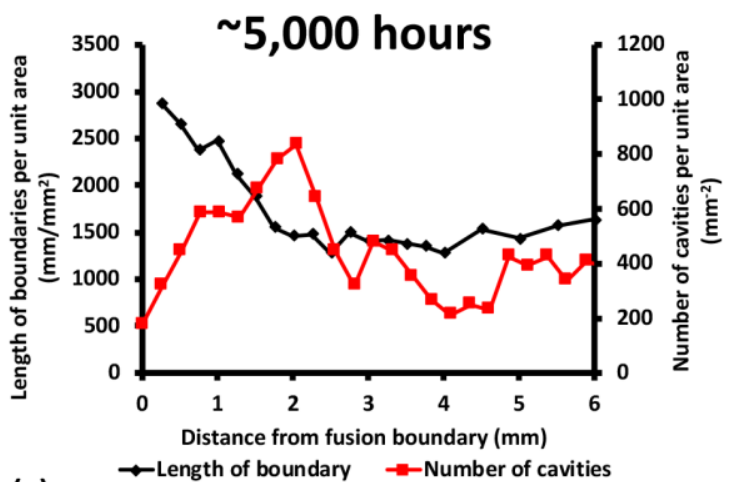

(a)
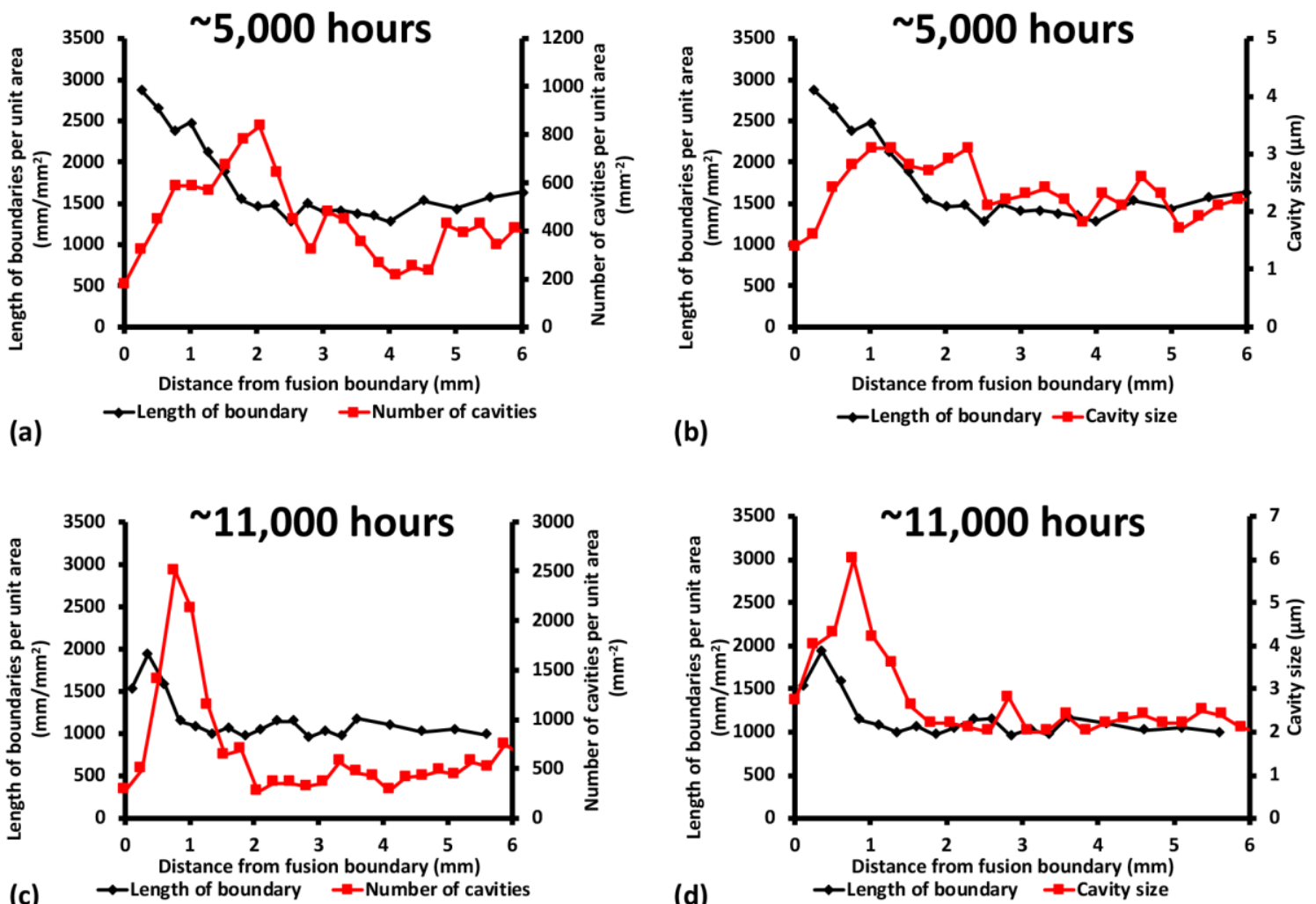

(c) $\rightarrow$-Length of boundary $\rightarrow$-Number of cavities

(d) $\rightarrow$ Length of boundary $\rightarrow$-Cavity size

Figure 6. Graphs comparing the length density of grain boundary $\left(>2^{\circ}\right)$ with (a and c) the number per unit area and (b and d) the size of cavities after ( $a$ and $b$ ) 5,000 hours and (c and d) 11,000 hours of 295 creep exposure.

3.5. Comparison between the $M_{23} C_{6}$ carbides and creep cavity

297 The $\mathrm{M}_{23} \mathrm{C}_{6}$ carbides across the HAZ were analysed by using ion induced SE imaging.

298 Figure 7 presents the micrographs showing the precipitate particles in the HAZ after

29911,000 hours of creep exposure. The number per unit area and size of the $\mathrm{M}_{23} \mathrm{C}_{6}$ carbides

300 were quantitatively analysed, with the results presented in Table 2. 

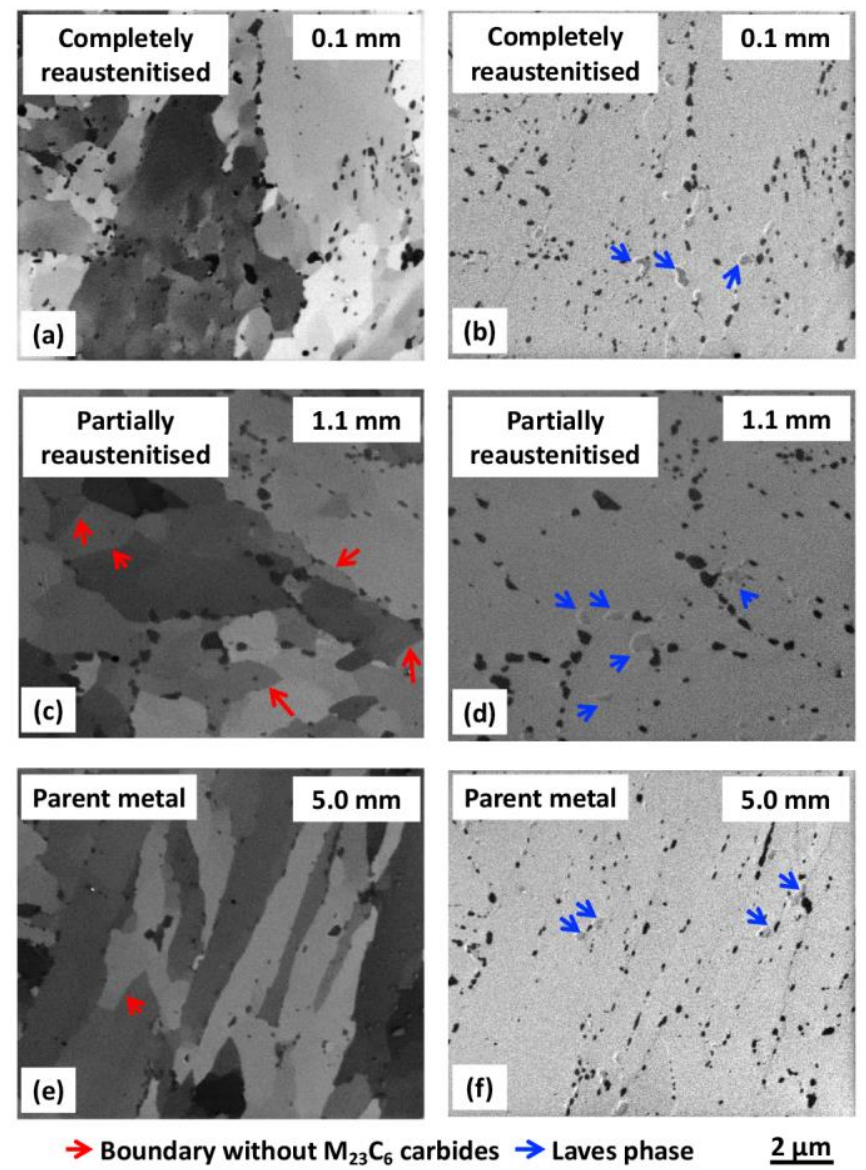

Figure 7. Ion induced SE micrographs showing the $\mathrm{M}_{23} \mathrm{C}_{6}$ carbides in (a, b) the CTZ, (c, $\left.d\right)$ the PTZ and (e, f) the parent metal after $\sim 11,000$ hours of creep exposure. The micrographs were collected from the regions at (a and b) $0.1 \mathrm{~mm}$, (c and d) $1.1 \mathrm{~mm}$ and (e and f) $5.0 \mathrm{~mm}$ from the fusion boundary. The micrographs as shown in (a, $\mathrm{c}, \mathrm{e})$ were collected without $\mathrm{XeF}_{2}$ gas to visualise grain structure, whilst (b, d, f) were collected with a $\mathrm{XeF}_{2}$ gas flow to enhance the contrast of the $\mathrm{M}_{23} \mathrm{C}_{6}$ carbides. The arrows indicate the grain boundaries where the particles are absent and the Laves phases appearing light grey.

Table 2. The number per unit area and mean size of the $M_{23} C_{6}$ carbides in the regions at $0.1 \mathrm{~mm}, 1.1$

$309 \mathrm{~mm}$ and $5.0 \mathrm{~mm}$ from the fusion boundary. Five micrographs were collected from each region, covering $310 \quad$ a total area of $\sim 600 \mu \mathrm{m}^{2}$.

\begin{tabular}{llll}
\hline Distance from the fusion line $(\mathrm{mm})$ & 0.1 & 1.1 & 5.0 \\
Number of particles per unit area $\left(\mathrm{mm}^{-2}\right)$ & $1,761,364$ & 845,170 & $1,534,091$ \\
Size of particles $(\mu \mathrm{m})$ & $0.18 \pm 0.10$ & $0.23 \pm 0.22$ & $0.17 \pm 0.14$
\end{tabular}

312 The ion induced SE micrographs collected at different conditions facilitate a direct

313 correlation between grain structure and the $\mathrm{M}_{23} \mathrm{C}_{6}$ carbides appearing dark grey [15,29]. 
314 Figures 7a, 7b, 7e and 7f show that the grain boundaries in the martensitic microstructure

315 are effectively stabilised by the carbide particles in the regions at $0.1 \mathrm{~mm}$ and $5.0 \mathrm{~mm}$ from

316 fusion boundary. However, a lack of precipitate particles on the boundaries were observed

317 in the HAZ region at $1.1 \mathrm{~mm}$ from the fusion boundary, Figures $7 \mathrm{c}$ and $7 \mathrm{~d}$. This region is

318 correlated with the location of peak damage present in the HAZ after 11,000 hours of

319 creep exposure. In particular, the precipitate particles at $1.1 \mathrm{~mm}$ from the fusion boundary

320 are evidently larger in size and lower in number density. This has been confirmed by the

321 results of quantitative analysis as presented in Table 2. The coarser precipitate particles are

322 present due to the partial dissolution of the pre-existing carbides in the original

323 microstructure during welding, followed by coarsening to large particles during the

324 subsequent PWHT and creep testing [5,6]. The retained $\mathrm{M}_{23} \mathrm{C}_{6}$ carbides also hinder the

325 formation of precipitates during PWHT and creep testing, leading to a lower number

326 density of carbides in the local regions.

327 The distribution of the $\mathrm{M}_{23} \mathrm{C}_{6}$ carbides on grain boundaries has been evaluated by

328 normalising the number density of carbides by using the length density of boundaries.

329 Figure 8 compares the trend of creep cavity to the variation of carbide distribution as a

330 function of the distance from fusion boundary.

331 Figure 8 shows that the normalised number density of the $\mathrm{M}_{23} \mathrm{C}_{6}$ carbides is considerably

332 lower in the HAZ as compared to the parent metal due to the refinement of grain structure.

333 In addition, the regions with larger cavity sizes are correlated with a lower number density

334 of carbides in both the specimens experiencing $\sim 5,000$ and $\sim 11,000$ hours of creep

335 exposure. The location of peak damage is also correlated with the regions showing the

336 lowest number density of carbides after 11,000 hours of creep exposure, Figure 8b. 

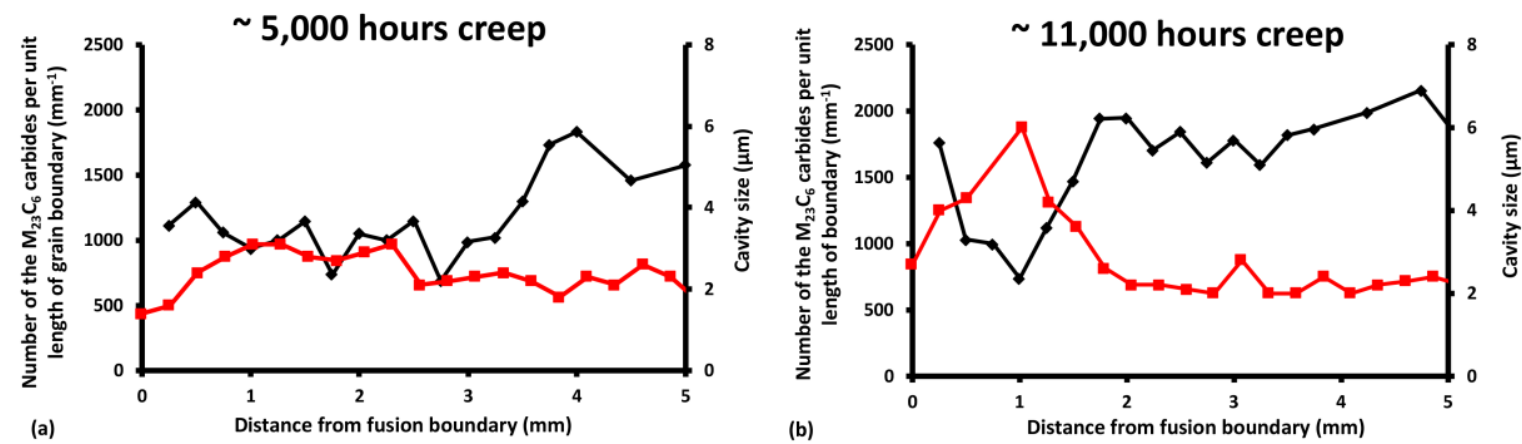

Number of the $\mathrm{M}_{23} \mathrm{C}_{6}$ carbides particle per unit length of substructure boundaries

338 Figure 8. The graphs comparing the trend of cavity size to the number density of the $\mathbf{M}_{23} \mathrm{C}_{6}$ carbides 339 per unit length of grain boundary $\left(>\mathbf{2}^{\circ}\right.$ ) after (a) $\sim \mathbf{5 , 0 0 0}$ and (b) $\sim \mathbf{1 1 , 0 0 0}$ hours of creep exposure.

340 3.6. Comparison between the Laves phase and creep cavity

341 Figure 9 presents the BSE micrographs showing the Laves phases within the HAZ and the 342 parent metal after 11,000 hours of creep exposure. The quantitative analysis for the 343 number density and size of these phases was also conducted with the results presented in 344 Table 3.
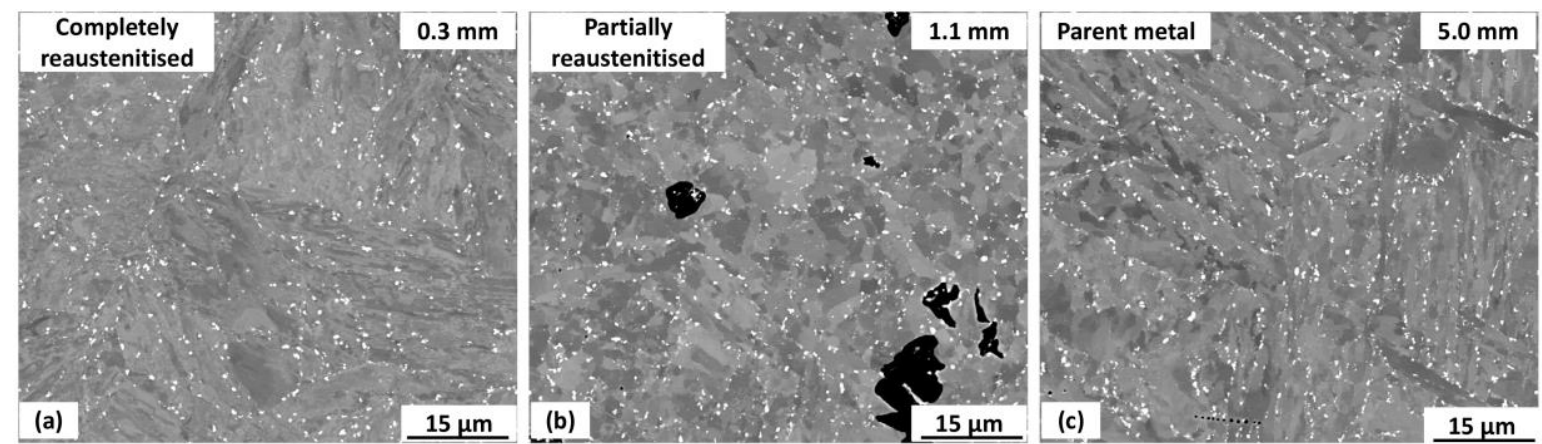

346 Figure 9. BSE micrographs showing the Laves phases (bright particles) in the regions at (a) $0.1 \mathrm{~mm}$, (b)

$347 \quad 1.1 \mathrm{~mm}$ and (c) $5.0 \mathrm{~mm}$ from the fusion boundary after $\sim 11,000$ hours of creep exposure.

348 Table 3. The number per unit area and mean size of the Laves phases at $0.1 \mathrm{~mm}, 1.1 \mathrm{~mm}$ and $5.0 \mathrm{~mm}$ 349 from the fusion boundary after $\sim \mathbf{1 1 , 0 0 0}$ hours of creep exposure. Five micrographs were collected from 350 each region, covering a total area of $\sim 10,000 \mu \mathrm{m}^{2}$.

\begin{tabular}{llll}
\hline Distance from the fusion boundary $(\mathrm{mm})$ & 0.1 & 1.1 & 5.0 \\
Number of particles $\left(\mathrm{mm}^{-2}\right)$ & 321,070 & 361,080 & 330,682 \\
\hline
\end{tabular}




\begin{tabular}{llll}
\hline Size of particles $(\mu \mathrm{m})$ & $0.44 \pm 0.23$ & $0.38 \pm 0.24$ & $0.44 \pm 0.24$ \\
\hline
\end{tabular}

352 Figure 9 shows the Laves phases appearing shiny bright in the BSE micrographs due to the 353 abundance of heavy elements such as W and Mo [33]. These phases are preferentially

354 distributed on grain boundaries. Table 3 shows that the number density of the Laves phases 355 is not significantly varied between the HAZ and the parent metal. The number density at

$3561.1 \mathrm{~mm}$ from fusion boundary is slightly higher as compared to the regions at 0.1 and 5.0

$357 \mathrm{~mm}$, whilst the average size is slightly smaller. The increased number density of Laves

358 phase is linked with a higher length density of grain boundary, particularly the high angle

359 boundary of austenitic grains. This has been evidenced in the previous studies that

360 demonstrate a higher length density of austenitic grain boundaries upon partial

361 reaustenitisation during welding [15,27]. The slightly smaller size of Laves phases in the

362 local regions is attributable to the retained $\mathrm{M}_{23} \mathrm{C}_{6}$ carbides being remained after incomplete

363 dissolution during welding. The presence of these particles is expected to cause a lower

364 content of $\mathrm{W}$ and Mo in solid solution and, in turn, hinder the formation of Laves phases.

365 Cavity association with $\mathrm{Al}_{2} \mathrm{O}_{3}, \mathrm{MnS}$ and $\mathrm{BN}$ phases

366 Figure 10 shows the $\mathrm{Al}_{2} \mathrm{O}_{3}, \mathrm{MnS}$ and $\mathrm{BN}$ phases in the $\mathrm{HAZ}$ after $~ 11,000$ hours of creep

367 exposure together with the EDX spectra confirming their chemical compositions. A close

368 association between creep cavities and the $\mathrm{Al}_{2} \mathrm{O}_{3}, \mathrm{MnS}$ and $\mathrm{BN}$ phases has been confirmed

369 after $\sim 11,000$ hours of creep exposure. In addition, the distribution characteristics of these

370 particles were quantitatively measured by using BSE imaging for a comparison between the

371 HAZ and the parent metal, Table 4. The quantitative analysis shows that the number

372 density and mean size of the $\mathrm{Al}_{2} \mathrm{O}_{3}, \mathrm{MnS}$ and $\mathrm{BN}$ phase particles are not significantly

373 varied between regions of the HAZ and the parent metal at $\sim 1.0$ and $\sim 5.0 \mathrm{~mm}$ from the

374 fusion boundary, respectively. 

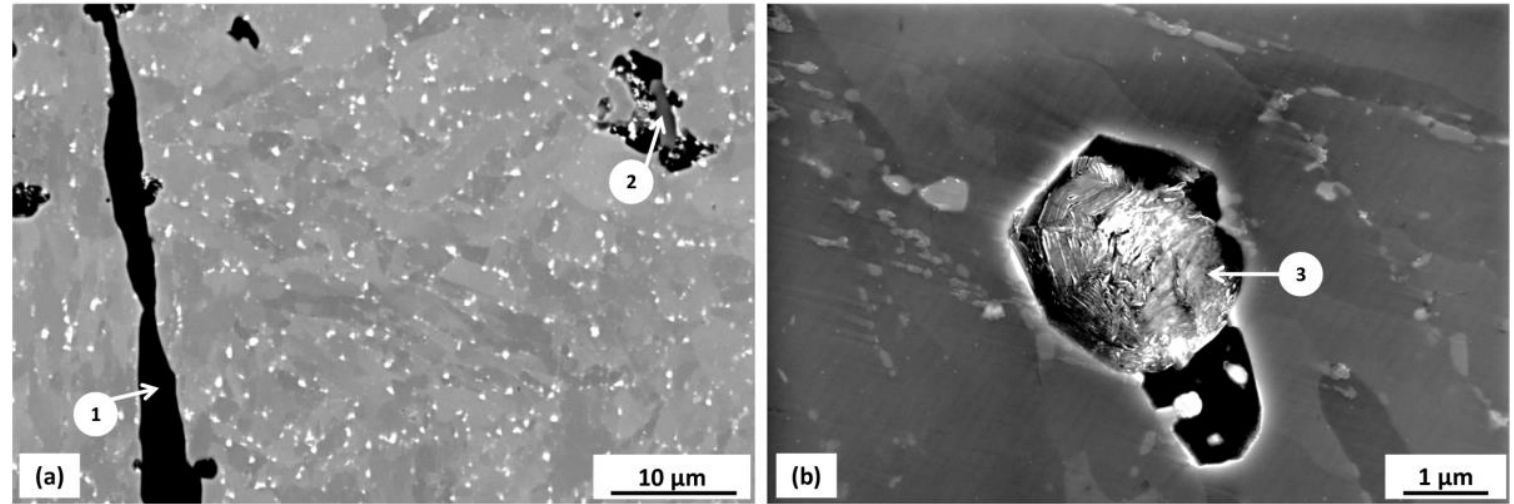

$$
\text { (c) }
$$
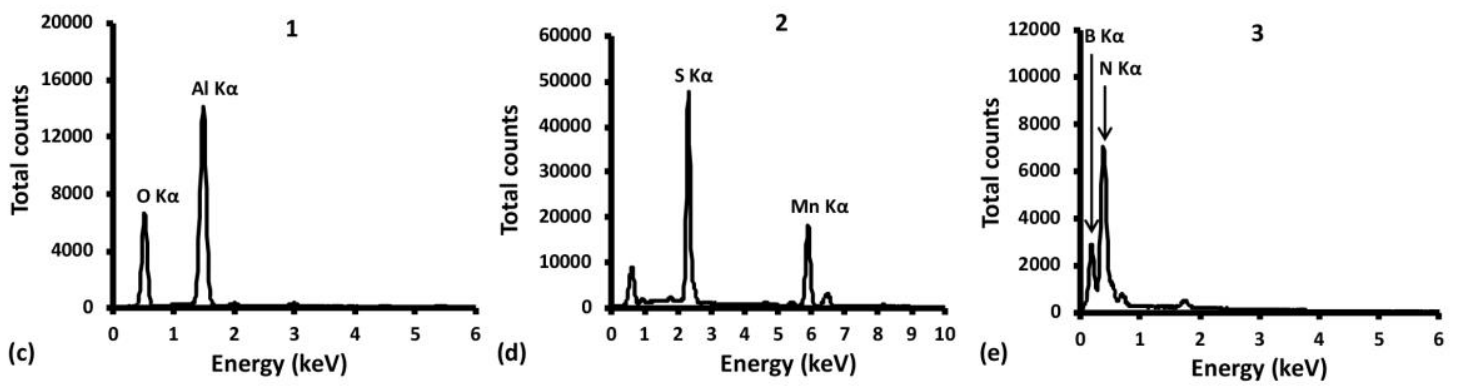

376 Figure 10. Micrographs showing the (a) $\mathrm{Al}_{2} \mathrm{O}_{3}$ and $\mathrm{MnS}$ particles and (b) BN phases within the cavities 377 after $\sim 11,000$ hours of creep exposure. The EDX spectra collected from these particles are shown in (c $378-\mathbf{e})$.

379 Table 4. The number per unit area and mean size of the $\mathrm{Al}_{2} \mathrm{O}_{3}, \mathrm{MnS}$ and $\mathrm{BN}$ particles at $1.1 \mathrm{~mm}$ and $380 \quad 5.0 \mathbf{~ m m}$ from the fusion boundary after $\sim \mathbf{1 1 , 0 0 0}$ hours of creep exposure. Five BSE micrographs were 381 collected from each region, covering a total area of $\sim \mathbf{2 0 0 , 0 0 0} \boldsymbol{\mu m}^{2}$.

\begin{tabular}{lll}
\hline Distance from the fusion boundary $(\mathrm{mm})$ & 1.0 & 5.0 \\
Number of particles per unit area $\left(\mathrm{mm}^{-2}\right)$ & $908 \pm 249$ & $1090 \pm 165$ \\
Size of particles $(\mu \mathrm{m})$ & $0.97 \pm 0.23$ & $0.83 \pm 0.17$ \\
\hline
\end{tabular}

\section{4. Discussion}

\subsection{Definition of damage susceptible region in the $H A Z$}

385 In comparison to the existing method used to categorise the general trend of microstructure 386 in the HAZ of steel welds [4,5], the previous studies have proposed a more accurate 387 description of the HAZ for the specific case of Grade 92 steel, as detailed in [15,27]. Figure 388 11a shows the microstructure in the HAZ of a single-pass weld as divided into three distinct 389 regions based on the characteristics of grain structure and secondary precipitate phases, i.e., 
the CTZ, the PTZ and the OTZ, [15]. Figure 11b further demonstrates a more complicated

391 case where there is an accumulated effect on microstructure arising from the multiple

392 experiences of thermal cycle as in a multi-pass weld [27].
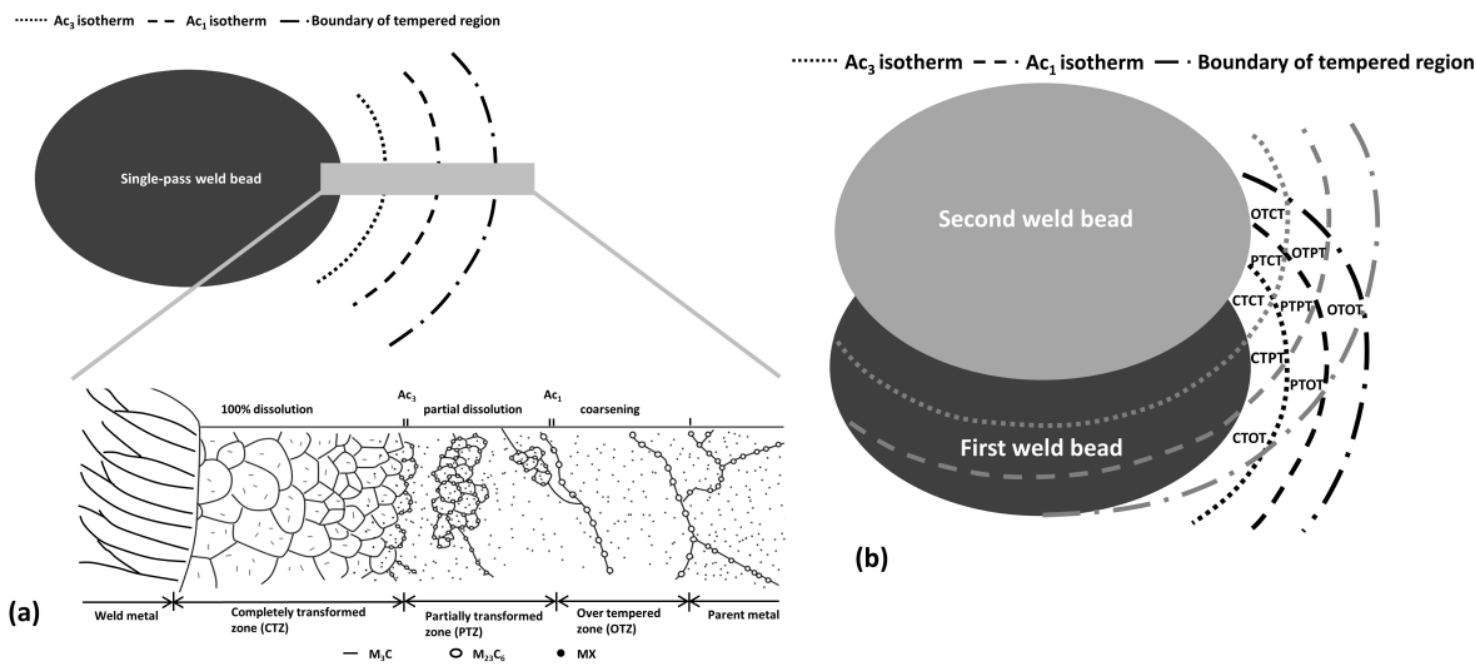

(b)

Figure 11. Schematic diagrams summarising the classification of the microstructures within the HAZs of (a) single-pass and (b) double-/multi-pass welds constructed by using Grade 92 steel as proposed in the previous studies [15,27]. The HAZ of a single-pass weld is divided into the Completely Transformed zone (CTZ), Partially Transformed Zone (PTZ) and Over-Tempered Zone (OTZ), which experience the thermal cycle with peak temperatures $>A c_{3}$, between $A c_{1}$ and $A c_{3}$ and $<A c_{1}$ temperatures, respectively. The $\mathrm{HAZ}$ of a double-/multi-pass weld is further classified by using the same designations to indicate the regions where the regions of CTZ, PTZ and OTZ are overlapped. For instance, 'CTCT' indicates the regions that experience two thermal cycles with peak temperatures both above the Ac3 temperature during welding.

403 As demonstrated in the HAZ of a multi-pass weld [27], thermal experiences with a peak 404 temperature above the $\mathrm{Ac}_{3}$ temperature lead to complete dissolution of the pre-existing 405 secondary precipitates in a completely reaustenitised matrix as in the regions of CTCT, CTPT, CTOT, PTCT and OTCT, Figure 11b. The resultant microstructures in these regions

407 are composed of the austenitic grains typically $\sim 50 \mu \mathrm{m}$ in size with no coarse particles

408 observed. The microstructure in the regions of PTPT, PTOT and OTPT contains coarse 409 particles of the retained secondary precipitates that were not completely dissolved after 410 experiencing the thermal cycles with peak temperatures between the $\mathrm{Ac}_{1}$ and the $\mathrm{Ac}_{3}$ 
411 temperatures [27]. The matrix in these regions varies from a refined, completely

412 reaustenitised grain structure to a duplexed microstructure containing coarse lath-like grains

413 as peak temperatures of weld thermal cycles decrease from the $\mathrm{Ac}_{3}$ to the $\mathrm{Ac}_{1}$ temperatures.

414 The microstructure in the regions of OTOT is not significantly varied from the parent

415 metal, while the hardness is lower and secondary precipitates are slightly coarsened [27]. In

416 comparison to the observations from the present study, it is clear that creep cavitation was

417 preferentially occurred in the regions experiencing thermal cycles with the inter-critical

418 peak temperatures between the $\mathrm{Ac}_{1}$ and the $\mathrm{Ac}_{3}$ temperatures, e.g. the regions of PTPT,

419 PTOT and OTPT. This is evidenced by the observation of coarse $\mathrm{M}_{23} \mathrm{C}_{6}$ carbides particles

420 in combination with a refined/duplexed grain structure, Figures 5 and 7.

421 Comparing with the existing studies on Grade 91 and Grade 92 steel welds, the reported

422 locations of creep rupture coincides with the regions showing the highest extent of creep

423 damage as presented in the current study. For instance, creep rupture is reported to take

424 place in the FG-HAZ region in Grade 92 steel welds as tested at $650^{\circ} \mathrm{C}$ with a stress level

425 of $<120 \mathrm{MPa}[34,35]$. Grade 91 steel welds are also ruptured at similar locations as tested

426 at $650^{\circ} \mathrm{C}$ in a stress range of $40-80 \mathrm{MPa}$ [36]. In these cases, coarse particles of secondary

427 precipitate in the matrix showing a refined grain structure were observed in the local

428 regions close to rupture surface (e.g. [36]). Following the conventional definition of the

429 HAZ in steel welds, it was hypothesized that the reported locations of creep rupture are

430 within the regions experiencing the thermal cycles with peak temperatures above the $\mathrm{Ac}_{3}$

431 temperature [4,5]. In the present case, the post-mortem analysis in the HAZ facilitates an

432 unambiguous link between the location of creep rupture and the initial microstructure in the

433 as-fabricated state, and further, the history of thermal experiences during welding. As

434 discussed above, the location of creep rupture has been confirmed in the regions

435 experiencing the thermal cycles with peak temperatures below the $\mathrm{Ac}_{3}$ and above the $\mathrm{Ac}_{1}$

436 temperatures.

\section{4.2. microstructural influence on creep cavitation}


438 To investigate the influence of microstructure on creep cavitation, the distribution of creep

439 cavity has been compared to the variation of microstructure in the HAZ. Table 5

440 summarises the overall gradient of microstructure as a function of the distance from fusion

441 boundary and the correlation between microstructure and creep damage.

442 Table 5. A summary of the microstructural factors that have been correlated with the distribution of

443 creep damage.

\begin{tabular}{ccl}
$\begin{array}{c}\text { Microstructural } \\
\text { property }\end{array}$ & $\begin{array}{c}\text { Figure } \\
\text { number }\end{array}$ & \multicolumn{1}{c}{ Observations } \\
\hline Hardness & 4 & $\begin{array}{l}\text { 1. Preferential creep cavity is not occurred in the softest region after } \sim 5,000 \\
\text { hours of creep exposure; } \\
\text { 2. The location of peak damage is correlated with the lowest hardness after } \sim \\
11,000 \text { hours of creep exposure. }\end{array}$ \\
\hline Grain structure & 5,6 & $\begin{array}{l}\text { Preferential creep cavity is not occurred in the region possessing the highest } \\
\text { length density of grain boundary. }\end{array}$ \\
\hline $\mathrm{M}_{23} \mathrm{C}_{6}$ carbides & 7,8 & $\begin{array}{l}\text { The regions showing a higher level of creep damage are correlated with a } \\
\text { lower number density of carbides both after } \sim 5,000 \text { and } \sim 11,000 \text { hours of } \\
\text { creep exposure. }\end{array}$ \\
\hline Laves phase & 9 & No significant variation between the HAZ and the parent metal. \\
\hline
\end{tabular}

$\mathrm{Al}_{2} \mathrm{O}_{3}, \mathrm{MnS}, \mathrm{BN} \quad 10 \quad$ Close association with cavities after $\sim 11,000$ hours of creep exposure;

445 The comparison between microstructure and creep cavity shows that cavitation is not

446 necessarily occurred in the regions with a lower hardness or a higher level of grain

447 boundary density, Table 5 . This is consistent with the observations from previous studies

448 showing that preferential creep cavitation is not occurred in the regions with lower hardness

449 or higher boundary density [5,23-26]. The lower hardness measured from the location of

450 peak damage after 11,000 hours of creep exposure is caused by the presence of

451 concentrated creep damage in the local regions.

452 An inhomogeneous distribution of the $\mathrm{M}_{23} \mathrm{C}_{6}$ carbides on lath and grain boundaries was

453 observed in the local regions due to incomplete dissolution of the pre-existing particles

454 during welding $[15,27]$. This is consistent with the observations from similar materials as

455 previously detailed in [6,37]. It is known that the major contribution of the $\mathrm{M}_{23} \mathrm{C}_{6}$ carbides

456 to creep resistance is increasing the stability of microstructure through a particle pinning

457 effect $[1,38]$. In this case, the lack of carbides on grain boundary and the coarsening of

458 precipitates during creep have a deleterious effect on creep strength in the local regions 
[39-41]. This is further related to concentrated cavitation due to strain localisation at an unfavourable stress state upon mechanical constraints from the adjacent regions in the HAZ and the parent metal that possess a higher creep strength [11,25].

462 The Laves phase particles that are grown above a critical size are related to the premature 463 creep failure in the HAZ [42]. The Laves phase particles that are large in size normally act 464 as the preferred sites for cavity nucleation. In addition, the Laves phases consuming $\mathrm{W}$ and 465 Mo deteriorate their effect of solid solution strengthening for the martensitic matrix [43]. 466 However, in this case, the Laves phases are relatively smaller in size and higher in number 467 density as appeared in the regions showing a higher extent of creep cavitation. This 468 suggests that these phases are not directly linked with the preferential cavitation in the PTZ.

469 Importantly, creep cavities are closely associated with the $\mathrm{Al}_{2} \mathrm{O}_{3}, \mathrm{MnS}$ and $\mathrm{BN}$ phases after $470 \sim 11,000$ hours of creep exposure. This observation is consistent with the existing studies 471 on $9 \%$ Cr steels as previously detailed in $[21,44]$. The large secondary phase particles 472 above a critical size are known as the preferred sites for cavity nucleation in $9 \% \mathrm{Cr}$ steels $473[21,30,44]$. In particular, a recent study on Grade 92 steel welds reveals a close association 474 between creep cavities and $\mathrm{BN}$ particles from a life fraction of $<50 \%$ to the stage close to 475 life end at a fraction of $>95 \%$ [22]. Detailed metallographic observations further reveal that 476 cavities were initiated via the link-up of micro-pores/defects presented on BN interfaces 477 from the initial as-fabricated condition prior to creep [22]. During creep, the cavities are 478 developed to larger sizes as present in the PTZ and, in turn, contribute to creep rupture in 479 the HAZ. This is related to a higher extent of interfacial decohesion on the BNs in the PTZ 480 that promotes the formation of cavities [22]. This further explains the observation of a 481 higher extent of creep cavitation in the PTZ (Figure 3), while the number density and size 482 of the $\mathrm{Al}_{2} \mathrm{O}_{3}, \mathrm{MnS}$ and $\mathrm{BN}$ particles are not significantly varied between $\mathrm{HAZ}$ and parent 483 metal (Table 4).

\section{Conclusions}

485 In the present study, preferential creep cavitation was observed in the HAZ of a multi-pass $4869 \% \mathrm{Cr}$ steel weld after high temperature creep exposure. A systematic comparison between 
creep cavity and HAZ microstructure has revealed a high susceptibility to creep cavitation

488 in the microstructures composed of refined grains in combination with a sub-optimal

489 distribution of the $\mathrm{M}_{23} \mathrm{C}_{6}$ carbides. However, the regions showing concentrated creep

490 damage are not correlated with the regions showing the lowest hardness or the most refined

491 grain structure. Creep cavities are nucleated on the large secondary phase particles such as

$492 \mathrm{Al}_{2} \mathrm{O}_{3}, \mathrm{MnS}$ and $\mathrm{BN}$. The local high density of creep cavities in the HAZ is thus a

493 consequence of strain localisation in the microstructures with low creep strength and large

494 secondary phase particles. The HAZ microstructures that are highly susceptible to creep

495 cavitation are generated upon thermal exposure with the peak temperatures between the $\mathrm{Ac}_{1}$

496 and the $\mathrm{Ac}_{3}$ transus temperatures during welding. Therefore, it is vital that alloy

497 composition, thermo-mechanical practices and final heat treatment are controlled to

498 produce weldments with optimal microstructures for an enhanced creep strength in the

499 HAZ.

500 Acknowledgement

501 This work was supported by the Electric Power Research Institute, Palo Alto, California,

502 USA. The authors gratefully acknowledge Dr Geoff West (WMG, Warwick University,

503 UK) for valuable contributions. The authors also acknowledge use of facilities within the

504 Loughborough Materials Characterisation Centre (LMCC).

\section{Data availability}

506 The raw data supporting the findings are available from the corresponding authors of this 507 study.

\section{References}

509 [1] P.J. Ennis, A. Czyrska-Filemonowicz, Recent advances in creep-resistant steels for 510 power plant applications, Sadhana. 28 (2003) 709-730.

511 [2] G.M. Marcello Consonni, Review of current practice for welding of Grade 92 steel, 
Weld. Cut. 11 (2013) 169-173.

513 [3] H. Rampaul, Pipe welding procedures, Industrial Press, New York, 2003.

514 [4] D.J. Abson, J.S. Rothwell, Review of type IV cracking of weldments in 9-12\% Cr

[5] J.A. Francis, W. Mazur, H. Bhadeshia, Review type IV cracking in ferritic power

[6] Y. Liu, S. Tsukamoto, T. Shirane, F. Abe, Formation mechanism of Type IV failure in high $\mathrm{Cr}$ ferritic heat-resistant steel-welded joint, Metall. Mater. Trans. A. 44

[7] S.K. Albert, M. Matsui, T. Watanabe, H. Hongo, K. Kubo, M. Tabuchi, Variation in the Type IV cracking behaviour of a high $\mathrm{Cr}$ steel weld with post weld heat treatment, Int. J. Press. Vessel. Pip. 80 (2003) 405-413.

8] F. Masuyama, M. Matsui, N. Komai, Creep rupture behavior of advanced 9-12\% Cr steel weldment, Key Eng. Mater. 171 (1999) 99-108.

[9] T. Sakthivel, M. Vasudevan, K. Laha, P. Parameswaran, K.S. Chandravathi, S.P. Selvi, V. Maduraimuthu, M.D. Mathew, Creep rupture behavior of $9 \mathrm{Cr}-1.8 \mathrm{~W}-0.5$ Mo-VNb (ASME grade 92) ferritic steel weld joint, Mater. Sci. Eng. A. 591 (2014) 111-120.

[10] J.S. Lee, K. Maruyama, Mechanism of microstructural deterioration preceding type IV failure in weldment of mod. 9Cr-1Mo steel, Met. Mater. Int. 21 (2015) 639-645.

[11] K. Shinozaki, D. Li, H. Kuroki, H. Harada, K. Ohishi, T. Sato, Observation of type IV cracking in welded joints of high chromium ferritic heat resistant steels, Sci. Technol. Weld. Join. 8 (2003) 289-295.

[12] M.E. Kassner, T.A. Hayes, Creep cavitation in metals, Int. J. Plast. 19 (2003) 17151748. 
[13] K. Laha, K.S. Chandravathi, P. Parameswaran, K.B.S. Rao, S.L. Mannan, Characterization of microstructures across the heat-affected zone of the modified 9Cr-1Mo weld joint to understand its role in promoting Type IV cracking, Metall. Mater. Trans. A. 38 (2007) 58-68.

[14] Y. Wang, R. Kannan, L. Li, Characterization of as-welded microstructure of heataffected zone in modified $9 \mathrm{Cr}-1 \mathrm{Mo}-\mathrm{V}-\mathrm{Nb}$ steel weldment, Mater. Charact. 118 (2016) 225-234.

[15] X. Xu, G.D. West, J.A. Siefert, J.D. Parker, R.C. Thomson, The influence of thermal cycles on the microstructure of Grade 92 steel, Metall. Mater. Trans. A. 48 (2017) 5396-5414.

[16] S.B. Wang, X.F. Chang, J. Key, New insight into high-temperature creep deformation and fracture of T92 steel involving precipitates, dislocations and nanovoids, Mater. Charact. 127 (2017) 1-11.

[17] J. Hald, Microstructure and long-term creep properties of 9-12\% Cr steels, Int. J. Press. Vessel. Pip. 85 (2008) 30-37.

[18] F. Abe, H. Araki, T. Noda, The effect of tungsten on dislocation recovery and precipitation behavior of low-activation martensitic $9 \mathrm{Cr}$ steels, Metall. Trans. A. 22 (1991) 2225-2235.

[19] D. Li, K. Shinozaki, H. Harada, K. Ohishi, Investigation of precipitation behavior in a weld deposit of $11 \mathrm{Cr}-2 \mathrm{~W}$ ferritic steel, Metall. Mater. Trans. A. 36 (2005) 107115.

[20] K. Sakuraya, H. Okada, F. Abe, BN type inclusions formed in high Cr ferritic heat resistant steel, Energy Mater. (2013).

[21] Y. Gu, G.D. West, R.C. Thomson, J. Parker, Investigation of creep damage and cavitation mechanisms in P92 steels, in: Adv. Mater. Technol. Foss. Power Plants Proc. from 7th Int. Conf., ASM International, 2014: pp. 596-606. 
563 [22] X. Xu, J.A. Siefert, J.D. Parker, R.C. Thomson, Localised creep cavitation on boron nitride in the heat affected zone of $9 \%$ Cr tempered martensitic steel welds, Mater. Des. 196 (2020) 109046.

[23] M. Tabuchi, T. Watanabe, K. Kubo, M. Matsui, J. Kinugawa, F. Abe, Creep crack growth behavior in the HAZ of weldments of W containing high Cr steel, Int. J. Press. Vessel. Pip. 78 (2001) 779-784.

[24] F. Abe, M. Tabuchi, M. Kondo, S. Tsukamoto, Suppression of Type IV fracture and improvement of creep strength of $9 \mathrm{Cr}$ steel welded joints by boron addition, Int. J. Press. Vessel. Pip. 84 (2007) 44-52.

[25] H. Hongo, M. Tabuchi, T. Watanabe, Type IV creep damage behavior in Gr. 91 steel welded joints, Metall. Mater. Trans. A. 43 (2012) 1163-1173.

[26] K. Kimura, Y. Takahashi, Evaluation of long-term creep strength of ASME Grades 91, 92, and 122 type steels, in: ASME 2012 Press. Vessel. Pip. Conf., American Society of Mechanical Engineers, 2012: pp. 309-316.

[27] X. Xu, G.D. West, J.A. Siefert, J.D. Parker, R.C. Thomson, Microstructural Characterization of the heat-affected zones in Grade 92 steel welds: double-pass and multipass welds, Metall. Mater. Trans. A. 49 (2018) 1211-1230.

[28] J.A. Siefert, J.P. Shingledecker, J.D. Parker, Optimization of vickers hardness parameters for micro-and macro-indentation of Grade 91 steel, J. Test. Eval. 41 (2013) 1-10.

[29] L. Li, R. MacLachlan, M. A. E. Jepson, R. Thomson, Microstructural evolution of boron nitride particles in advanced 9Cr Power plant steels, Metall. Mater. Trans. A. 44 (2013) 3411-3418.

[30] J. Parker, Factors affecting Type IV creep damage in Grade 91 steel welds, Mater. Sci. Eng. A. 578 (2013) 430-437.

[31] F. Abe, T.U. Kern, R. Viswanathan, Creep-resistant steels, Woodhead Pub., 2008. 
[32] J. Lin, Y. Liu, T.A. Dean, A review on damage mechanisms, models and calibration methods under various deformation conditions, Int. J. Damage Mech. 14 (2005) 299-319.

[35] W. Xue, P. Qian-gang, L. Zhi-jun, Z. Hui-qiang, T. Yong-shun, Creep rupture behaviour of P92 steel weldment, Eng. Fail. Anal. 18 (2011) 186-191.

\section{[36] T. Watanabe, M. Tabuchi, M. Yamazaki, H. Hongo, T. Tanabe, Creep damage} evaluation of $9 \mathrm{Cr}-1 \mathrm{Mo}-\mathrm{V}-\mathrm{Nb}$ steel welded joints showing Type IV fracture, Int. J. Press. Vessel. Pip. 83 (2006) 63-71.

[37] R.C. Maclachlan Sanchez-Hanton, J.J., Thomson. R.C., The effect of simulated post weld heat treatment temperature overshoot on microstructural evolution in P91 and P92 power plant steels, in: Adv. Mater. Technol. Foss. Power Plants - Proc. from 6th Int. Conf., ASM International, 2011: 787-799.

[38] K. Maruyama, K. Sawada, J. Koike, Strengthening mechanisms of creep resistant tempered martensitic steel, ISIJ Int. 41 (2001) 641-653.

[39] K. Sawada, M. Bauer, F. Kauffmann, P. Mayr, A. Klenk, Microstructural change of 9\% Cr-welded joints after long-term creep, Mater. Sci. Eng. A. 527 (2010) 14171426.

[40] H.G. Armaki, R. Chen, K. Maruyama, M. Igarashi, Creep behavior and degradation of subgrain structures pinned by nanoscale precipitates in strength-enhanced 5 to 12 pct Cr ferritic steels, Metall. Mater. Trans. A. 42 (2011) 3084-3094. 
615 [41] B.F. Dyson, Continuous cavity nucleation and creep fracture, Scr. Metall. 17 (1983)

616 31-37.

617 [42] L. Zhao, H. Jing, L. Xu, J. An, G. Xiao, D. Xu, Y. Chen, Y. Han, Investigation on

618 mechanism of type IV cracking in P92 steel at $650^{\circ} \mathrm{C}$, J. Mater. Res. 26 (2011) 934619943.

620 [43] W. Yan, W. Wang, Y.Y. Shan, K. Yang, Microstructural stability of 9-12\% Cr 621 ferrite/martensite heat-resistant steels, Front. Mater. Sci. 7 (2013) 1-27.

622 [44] T. Shrestha, M. Basirat, I. Charit, G.P. Potirniche, K.K. Rink, Creep rupture 623 behavior of Grade 91 steel, Mater. Sci. Eng. A. 565 (2013) 382-391.

624

625

626 